\title{
RESENHA
}

\section{OS milagres marianos em prol do Rei Sábio de Leão e Castela}

REVIEW

Marian miracles for the wise king of León and Castile

Alex Rogerio Silva*

LEÃO, Ângela Vaz (Org.). Cantigas Autobiográficas de Afonso X, o Sábio. Belo Horizonte: Ed. PUC Minas, 2016. 248p.

Nos séculos XII e XIII, floresceu, na Europa, o culto mariano, que ficou marcado por inúmeras manifestações artísticas e devocionais à figura de Maria, Mãe de Jesus. No tocante à arquitetura, o nome de Maria apareceu ligado à construção de grandes igrejas e catedrais como a Notre Dame de Paris, Notre Dame de Chartres, etc. $\mathrm{Na}$ literatura, foram escritas hagiografias com diversos tipos de milagres realizados em diferentes localidades até então conhecidas, bem como escritos com o intuito de celebrar as virtudes da Virgem Maria. No mesmo período, desenvolveu-se uma poesia de caráter religioso que remontava às cortes trovadorescas e que tinha como objetivo cantar louvores. Segundo Viviane Cunha, "Os temas mais constantes dessa poesia são o louvor à Virgem Maria, a quem são dirigidos expressivos elogios, e as narrativas de milagres, nos quais Ela é a mediadora entre Deus e os homens" (CUNHA, 2011, p. 17).

Nesse momento, passaram a figurar três poetas/trovadores da Virgem: Gautier de Coincy que compôs a obra Les miracles de Nostre Dame; Gonzalo de Berceo que organizou a obra Milagros de Nuestra Señora e D. Afonso X, Rei de Leão e Castela que empreendeu o projeto intitulado, Cantigas de Santa Maria, obra esta que abordaremos nesta resenha.

As Cantigas de Santa Maria são um conjunto formado por aproximadamente 420 cantigas escritas em verso, aplicada à métrica do zéjel ${ }^{1}$, na qual são compostas de

\footnotetext{
* Mestre em História e Cultura Social pela Universidade Estadual Paulista Júlio de Mesquita Filho (UNESP).
} 
narrativas de milagres e composições que louvam a Virgem. Dentre as cantigas de milagre, em algumas delas, são elencados episódios no qual o rei ou membros de seu círculo de relações são agraciados com alguma intervenção de Santa Maria.

São essas cantigas que Ângela Vaz Leão e seus alunos integrantes do Grupo de Pesquisa, "Cantingueiros ${ }^{2}$ de Santa Maria", na Pontifícia Universidade Católica de Minas Gerais, se debruçaram e, em dezembro de 2016, publicaram a antologia intitulada, Cantigas autobiográficas de Afonso X, o sábio, pela Editora PUC Minas.

A obra, organizada por Ângela Vaz Leão, teve a colaboração de Carolina Antunes, Fransmarina Lourenço Assunção, Heloísa Guaracy Machado, Keyla Luciene Marques Quintas, Maria Cristina B. Marinho Baracat, Meire Mara Coelho Nogueira e Renato Cardoso Corgosinho e constitui-se de tradução e análise de 34 poemas

[...] que revelam episódios da vida de D. Afonso X ou de alguém quer de sua família quer de seu convívio, com: seu pai D. Fernando III, o Santo; sua mãe D. Beatriz de Suábia; seu irmão caçula D. Manuel; sua filha Berenguela, monja cisterciense em Burgos; e seus servidores encarregados da caça e pesca, portanto ligados à mesa da família (LEÃO, 2016, p. 11)

As primeiras páginas já impressionam o leitor devido à reprodução de 5 páginas iluminadas do "Códice E" das Cantigas de Santa Maria pertencentes à Biblioteca do Escorial conhecidas como "códice rico", devido às numerosas iluminuras e por conter 200 cantigas das 420 que compõem o conjunto de cantigas afonsinas (LEÃO, 2007, p. $29,30)$.

A introdução, escrita por Ângela Vaz Leão, relata o trabalho desenvolvido pelo Grupo de Pesquisa, "Cantingueiros de Santa Maria", na Pontifícia Universidade Católica de Minas Gerais, sob a sua orientação, bem como sobre as teses e dissertações com temas relacionados às Cantigas de Santa Maria que já foram defendidas na

\footnotetext{
${ }^{1}$ Zéjel é um tipo de composição poética medieval de origem moçárabe ou hispano-muçulmana, que teria sido criado por Mucáddam ben Muáfa, el Cabri, um poeta andaluz, natural de Cabra, região de Córdoba, entre o final do século IX e o início do século X. Compõe-se o zéjel, na sua forma canônica, dos seguintes elementos: a) Um refrão ou estribilho que, na maioria dos casos, é um dístico monorrimo e, como é típico do refrão, se repete após cada estrofe; b) Um número variável de quadras, cujo os três primeiros versos rimam entre si, mudando as rimas de estrofe para estrofe, e cujo quarto verso repete a rima do refrão (LEÃO, 2011, p. 27-28).

2 "Cantingueiros" - a palavra "cantingueiro" é um neologismo ainda não registrado (pelo menos em 2016), em nenhum dos dicionários de língua portuguesa. Encontram-se os verbetes "cantor" e "cantador', derivados de "canto", mas não "cantingueiro", originado de "cantiga". O neologismo, segundo cremos, foi criado nos Estados Unidos, no seio de um grupo de scholars que vêm publicando suas pesquisas sobre as Cantigas de Santa Maria em excelentes trabalhos, hoje, conhecidos em todo o mundo. Para divulgá-los, esse grupo criou também uma revista monográfica, o Bulletin of the Cantingueiros de Santa Maria, cujo primeiro número foi publicado em outono de 1987 (LEÃO, 2016, p. 10, nota de rodapé).
} 
instituição, além disso, a filóloga cita outras obras da mesma temática publicadas anteriormente pela autora. Em seguida, Ângela Vaz Leão explica a estrutura do estudo das cantigas nesta introdução, na qual foi dividida em três partes: a primeira delas no que tange ao texto em galego-português, ao ser feita a transcrição do original, dividindo em estrofes e, em seguida, a tradução em prosa para o português contemporâneo no mesmo estilo, fragmentado, de modo a facilitar o entendimento por parte do leitor. Em seguida, são tecidas notas explicativas no tocante ao texto, de forma a elencar as especificidades do poema em questão, sejam de caráter linguístico ou literário, sejam sob o aspecto geográfico ou histórico; e a terceira parte consiste na tradução integral em prosa do poema de forma a fornecer ao leitor uma ideia total desse texto literário.

Segundo Ângela Vaz Leão:

Essa metodologia, que parece repetitiva, teve por finalidade atender a necessidades diferentes, de diferentes leitores. Por exemplo: alguém poderá optar pela leitura segmentada da cantiga, somente em galego-português; outro optará pela leitura da tradução portuguesa, igualmente fragmentada, comparando-a com o original; outro, não interessado na parte filológica, poderá limitar-se à leitura da tradução integral da cantiga (LEÃO, 2016, p. 12).

Em seguida, é apresentada uma breve biografia de D. Afonso X, Rei de Leão e Castela, escrita pela Dr ${ }^{\mathrm{a}}$. Heloísa Guaracy Machado, professora do Departamento de História da Pontifícia Universidade Católica de Minas Gerais e, também, integrante do Grupo de Pesquisa, "Cantigueiros de Santa Maria". A biografia composta de 11 páginas fornece ao leitor iniciante, ou mesmo experiente, um panorama consistente sobre a vida do Rei Sábio, seu apreço pelo conhecimento, pela cultura e suas dificuldades para governar, bem como mostra quais cantigas relatam determinados episódios da vida de D. Afonso X, podendo suscitar ao leitor comparações da biografia apresentada com os poemas afonsinos.

Posteriormente, são apresentadas as cantigas autobiográficas de D. Afonso X e a análise linguística, de aspectos literários e históricos, a saber: Prólogo B, Cantiga 18, 97, 122, 142, 169, 209, 215, 221, 235, 243, 256, 257, 276, 279, 292, 295, 297, 299, 321, 324, 328, 345, 348, 349=387, 354, 361, 366, 367, 376, 377, 382, 386 e 401. A análise é riquíssima e demonstra um profundo conhecimento dos autores no processo de tradução, assim como sobre aspectos literários e históricos que permeiam a obra e a vida do Rei Sábio. 
É apresentado, também, 3 anexos: a árvore genealógica da família de D. Afonso $\mathrm{X}$ e dois mapas da Península Ibérica - um deles mostra os reinos medievais que formariam posteriormente a Espanha, e o segundo, a Península Ibérica no final do século XIII, onde os reinos cristãos reconquistaram grande parte dos territórios que tinham sido invadidos pelos mouros, exceto Granada -, e nesse movimento de Reconquista, D. Afonso $\mathrm{X}$ teve um papel importante para esta reconfiguração geográfica.

Na conclusão do livro, Ângela Vaz Leão (2016, p. 227) enfatiza o compromisso intelectual do Rei Sábio, ao se dedicar a vários tipos de saberes, desde a História, passando pelo Direito Civil, e chegando aos jogos e entretenimentos. Além disso, ela dedica esta obra

[...] à apreciação de aspectos dessas cantigas, e um convite a todos aqueles que almejam o conhecimento e buscam, na leitura desses poemas, aprofundar temas atuais em torno da fé, do poder, das relações sociais, e, sobretudo, da natureza humana - tudo isso relacionado com a figura de D. Afonso X, a quem, não por acaso, a História atribuiu o epíteto de Sábio (LEÃO, 2016, p. 227-228).

Caminhando para o final, constatamos que este foi um trabalho de fôlego empreendido pelos alunos do Grupo de Pesquisa, "Cantingueiros de Santa Maria", coordenados pela Prof. Ângela Vaz Leão, e que nos brinda com uma publicação reflexiva acerca da vida de um rei na Idade Média ibérica, suas relações sociais, fé, angústias, mas também sua sede pelo conhecimento e pela cultura, em um mundo onde as guerras tomavam grande parte do tempo dos governantes. Tendo isso em vista, esta obra se apresenta como uma inestimável referência àqueles que se interessam pela temática das Cantigas de Santa Maria e também sobre a vida do rei D. Afonso X, o Sábio. Nesse sentido, essa obra desafia o especialista mais rigoroso a encontrar algum demérito. 


\section{REFERÊNCIAS}

CUNHA, Viviane. Prefácio. In: LEÃO, Ângela Vaz. Cantigas de Afonso X a Santa Maria (antologia, tradução e comentários). Belo Horizonte: Veredas \& Cenários, 2011.

LEÃO, Ângela Vaz (Org.). Cantigas Autobiográficas de Afonso X, o Sábio. Belo Horizonte: Ed. PUC Minas, 2016.

LEÃO, Ângela Vaz (Org.). Cantigas de Afonso X a Santa Maria (antologia, tradução e comentários). Belo Horizonte: Veredas \& Cenários, 2011.

LEÃO, Ângela Vaz (Org.). Cantigas de Santa Maria de Afonso X, O Sábio. Aspectos culturais e literários. São Paulo: Veredas \& Cenários, 2007. 